\title{
RETOS QUE PLANTEA LA ARMONIZACIÓN CONTABLE EN LA FRONTERA COLOMBO-VENEZOLANA, A LA FORMACIÓN DE ESTUDIANTES DE CONTADURÍA PÚBLICA DE LA REGIÓN NORORIENTAL DE COLOMBIA*
}

Carlos Arturo Gómez Trujillo**

\footnotetext{
* Semillero APIC: Academia Permanente en Investigación Contable

Estudiantes investigadores: Mary Luz Peñaloza Gélvez, Yudith Margarita Galvis Higuera, Shirley Estefanía Gaviria Portilla, Dora Liliana Capacho Gélvez, Ewars Ferley Meneses Jaimes, Rafael Enrique Ariza Gonzales. Director: Carlos Arturo Gómez Trujillo.

** Docente Facultad de Ciencias Económicas y Empresariales Universidad de Pamplona. Pamplona Colombia. E-mail: cargotru@hotmail.com
} 


\section{RETOS QUE PLANTEA LA ARMONIZACIÓN CONTABLE EN LA FRONTERA COLOMBO-VENEZOLANA, A LA FORMACIÓN DE ESTUDIANTES DE CONTADURÍA PÚBLICA DE LA REGIÓN NORORIENTAL DE COLOMBIA}

\section{RESUMEN}

Geográficamente el departamento Norte de Santander esta ubicado estratégicamente, siendo el sector fronterizo de mayor interés e importancia para la relación bilateral, promovido y estimulado desde las regiones, Cúcuta (Colombia) y San Cristóbal (Venezuela), que se han consolidado como centros motrices de la economía regional-fronteriza; lo cual ha permitido que se configure el más importante eje comercial transfronterizo en la subregión andina, donde tiene lugar uno de los procesos de integración más intensos con repercusiones a escala internacional. Con el fin de explorar nuevos campos que favorezcan la formación de los profesionales del área contable, la propuesta tiende a buscar espacios de estudio local, regional y binacional, ofreciendo a estudiantes y profesionales, posibilidades de unificar sobre los contenidos de los programas contables, que favorezcan procesos de formación integral.

\section{Palabras Claves: Globalización,} Armonización, Estandarización, Zonas de frontera, Pensamiento Contable, Formación, Desafíos, Contaduría Pública, Investigación, Integralidad.

\begin{abstract}
Geographically the Norte de Santander department is strategically located, being the border area of greatest interest and importance to the bilateral relationship, promoted and encouraged from the regions, Cucuta (Colombia) and San Cristobal (Venezuela), which were consolidated as centers of driving the regional economy-border, which has made it possible to configure the most important axis cross-border trade in the Andean subregion, which takes place one of the most intense integration processes with implications on an international scale. In order to explore new fields that promote the training of professionals in the accounting area, the proposal aims to seek opportunities for study local, regional and binational, offering students and professionals, opportunities to unify on the contents of the accounting programs, promote comprehensive training processes.
\end{abstract}

KEY WORDS: Globalization, Harmonization, Standarization, Frontier Zone, border areas, Formation, Public Accounting, Challenges.

Face IssN $1794-9920$

Recepción: Abril de 2008

Revisión: Mayo de 2008

Aceptación: Mayo de 2008 


\section{INTRODUCCIÓN}

Actualmente, el mundo se enfrenta a una sociedad en red denominada Globalización. Toni Comin, primero en definir este término, hace referencia a Globalización, como el proceso fundamentalmente económico, que consistía -en su momento- en "la creciente integración de las distintas economias nacionales en un único mercado capitalista global'. En nuestros días, el termino Globalización abarca diversos factores y está estrechamente ligado al comercio internacional, de donde surge a su vez el proceso de armonización. Con la armonización se busca eliminar barreras existentes entre las naciones para lograr la consolidación del comercio global.

Hoy más que nunca, las distancias son extraordinariamente cortas entre las naciones y el concepto de frontera pasó de ser una simple línea divisoria para ser motivo de relaciones dinámicas en todos los aspectos económicos, políticos, sociales y culturales. Por tanto, decir que las zonas de Frontera son la puerta de entrada al desarrollo de un país, es darles la importancia que tienen en la economía de una nación. Esto implica una mirada a la cotidianidad de la vida en las fronteras, en donde el comercio fluye por sí mismo en las llamadas: Zonas de Integración Fronteriza. La armonización contable en este proceso de intercambios comerciales, surge como necesidad de adaptarse a nuevas exigencias, nuevos convenios entre regiones, países y empresas internacionales.

Los profesionales en contaduría y los que aun están en procesos de formación encuentran en esta situación, la posibilidad de ampliar sus horizontes a través de la continuación de su formación profesional en el país vecino y de ampliar el ejercicio de la profesión a nivel binacional. La realidad de la globalización, desafía la rama contable y financiera en Colombia, generando el espacio y las condiciones para reflexionar, analizar, debatir, proponer y asumir nuevos retos, tanto en el orden profesional, normativo como de formación, dada la responsabilidad social que este proceso implica.

${ }^{1}$ http:/ / es.wikipedia.org. Termino: Globalización. Consultado 9 de enero de 2007. 


\section{GLOBALIZACIÓN}

\section{Concepto:}

La globalización es un fenómeno que ha adquirido relevancia en los últimos años. Puede describirse como la internacionalización del conocimiento y de las actividades humanas en general. En ese sentido, el fenómeno comprende la internacionalización de las comunicaciones, de la cultura $y$, fundamentalmente, de la economía y dentro de esta última, del intercambio comercial. Factores políticos y el avance tecnologico, entre otros, han determinado la eliminación práctica de las fronteras físicas y de restricciones formales al movimiento de personas, bienes, imágenes e ideas. En la actualidad, todas las personas y entidades tienen la posibilidad de acceder 0 vincularse "en tiempo real" o con facilidad, a hechos, personas y entidades, ocurridos o localizados en cualquier parte del universo.

En Latinoamérica, este proceso de intercambio comercial y fortalecimiento del mismo, surge a partir del Tratado de Montevideo, evento en el cual se da la creación de la ALALC $^{2}$, hacia el año de 1960. Precisamente dos de los objetivos principales de la ALALC, inmersos en la creación de la zona de libre comercio era desaparecer sucesivamente los aranceles y establecer ese mercado común entre sus miembros, que en dicho momento fueron: Argentina, Brasil, Chile, México, Paraguay, Perú y Uruguay, grupo al que un año después se adhiere Colombia y posteriormente Venezuela y Bolivia en 1966 y 1967 respectivamente. Sin embargo, la crisis de la década del 70 y la creación de nuevos organismos como el grupo andino, posteriormente La (Comunidad Andina de Naciones) CAN, condujeron al fin de dicho intento.

A nivel mundial está el Acuerdo General sobre Aranceles y Comercio, llevado a cabo en Ginebra en 1947. El GATT (General Agreement on Tarifs and Trade), permitió a pesar de ser un acuerdo provisional y no un organismo como tal, desarrollar una serie de conferencias a partir de esta fecha. En su octava conferencia arancelaria, llamada Ronda Uruguay, iniciada el 15 de Septiembre de 1986 y clausurada el 15 de Diciembre de 1993, el GATT es sustituido por la Organización Mundial del Comercio (OMC). La OMC reúne el desarrollo y los logros del GATT, los revisa y mejora, siendo ya una organización internacional con plenos poderes. Su finalidad es aumentar el flujo comercial en el planeta, ello implica la supervisión de las prácticas comerciales a nivel

\footnotetext{
2Asociación Latinoamericana de Libre Comercio (ALALC). Organismo intergubernamental latinoamericano existente entre 1960-1980. Creado el 18 de febrero de 1960 por el Tratado de Montevideo. Reemplazado por la ALADI. Tomado el 3 de febrero de 2008 http://es.wikipedia.org/wiki/Asociaci\%C3\%B3n_Latinoamericana_de_Libre_Comercio.
} 
mundial y también, juzgar los litigios comerciales presentados por los Estados miembros. La OMC, en vigencia desde el 1 de Enero de 1995, contaba con 76 países miembros, entre los cuales está Colombia. En el año 2003, el número de países llega a $\operatorname{los} 148$.

Estados Unidos de Norte América, es el país sede de la OMC, sin embargo, se considera que el poder que ejerce frente a esta organización, ha generado desigualdad ante las demás naciones y hacen de esta un ente poco equitativo a la hora de intervenir en acuerdos que favorezcan a otras naciones y que de algún modo, reduzcan los intereses particulares de este país. En la V Conferencia Ministerial realizada en el 2003 en Cancún (México), fracasaron los intentos por reducir los subsidios agrícolas y los aranceles en los países ricos para permitir una mayor exportación de las naciones pobres, dependientes en gran medida de sus cultivos. Lo anterior ha impulsado la conformación de sectores oponentes a la intervención de los EE.UU en el desarrollo de economías pequeñas, aún cuando sea en "acuerdo" con el país.

La globalización, no es algo nuevo. Desde los fenicios y hasta la crisis financiera de 1929, el comercio se desarrolló libre y crecientemente; lo nuevo vino después de la Segunda Guerra Mundial. Diversos eventos políticos acaecidos al final de la década del 80 en Europa, junto con nuevas estrategias empresariales y el tremendo desarrollo tecnológico, han puesto nuevamente en primer plano la importancia del comercio internacional para el desarrollo de los paises y han exaltado consecuentemente, la conveniencia de adoptar políticas económicas abiertas con la finalidad de promoverlo. Por otra parte, una nueva concepción sobre los papeles del estado y del sector privado en la economía, han dado impulso a la idea del intercambio comercial sin fronteras como una de las manifestaciones más notorias de la globalización. En 1992 se cumplió 500 años de globalización, definida también colonización; antes con carabelas, espadas y cruces, boy con parabólicas, fuerzas de despliegue rápido y neoliberalismo. ${ }^{3}$

\section{ARMONIZACIÓN CONTABLE}

Dentro del contexto normativo en materia contable se precisa la necesidad de conciliación de los diferentes enfoques, bajo la salvedad de que sus procesos son diferentes. De un lado está la estandarización de lo contable, emergente de la necesidad de hablar un mismo idioma normativo y procedimental, que permita entender a un conjunto de personas, formadas bajo diversos contextos y escuelas, un hecho económico- financiero ocurrido en un ente, común para ellos. Este proceso, aun cuando importante en los países que hacen parte de una integración y apertura de mercados, no está exento de controversias, ya que en el espacio de implementación, no toma en cuenta entornos económicos y sociales para su aplicación. Al respecto Rafael Franco Ruiz afirma en su libro Contabilidad Integral en el capítulo 4 que "cualquier

3 TALLA RAMOS, S. La Globalización y La Armonización Contable.

http://atenea.unicauca.edu.co/ gcuellar/globalizacion.htm . Consultado el 3 de febrero de 2008 
adopción normativa es inconveniente, es delegar en entidades privadas extranjeras la función legislativa, hoy privativa del Estado. Se hace necesario establecer bases comprensivas comunes para los mensajes contables, pero estas se deben concebir en el plano de la armonización o ajuste, que se refieren a las recomendaciones y convenios internacionales y de organismos multilaterales en ese plano, Colombia ya resolvió el asunto a partir de la normatividad contable establecida en 1993".

Por su parte, armonizar y/o adaptar, es entendido como el proceso opuesto al de estandarizar, en tanto implica la reconciliación de dos puntos de vista diferentes, permitiendo evaluar las condiciones de los sistemas económicos incluyentes y dejando a las partes tomar las decisiones, más no imponiendo una serie de normas. En el Diccionario de la Lengua Española, armonizar significa "poner en armonía o hacer que no discuerden o se rechacen dos o más partes de un todo o dos o más cosas que deben concurrir al mismo fin". De lo anterior se deducen diferencias entre uno y otro proceso. Mientras en el primero hay una cierta imposición, en el segundo se observa por el contrario, conciliación.

En sentido Contable, la armonización sería "el poner de acuerdo, el conciliar las normas existentes", el proceso de conciliación de las diferentes prácticas de los países que pueden alcanzar una uniformidad y que ha llevado a una normalización contable que no sea rígida. La armonización contable depende de factores externos como el neoliberalis $\mathrm{mo}^{4}$, los tratados internacionales y en últimas, es un elemento indispensable en la búsqueda de la penetración de nuevos mercados. Por otro lado, mientras en los países desarrollados se busca mejorar el sistema y extenderlo, en los tercermundistas se asume porque llega como consecuencia de la influencia del más poderoso ${ }^{5}$. La globalización es una incongruencia: sus consecuencias excluyen a la mayoría de la población mundial.

La aplicación del proceso de armonización no es un proceso fácil de llevar a cabo, en tanto implica cambios y transformaciones para los cuales en muchas circunstancias no hay preparación. Dejar de lado la forma como se procede para asumir lo nuevo y reducir al máximo las diferencias, sobre todo aquellas que son impedimento al flujo

\footnotetext{
${ }^{4} \mathrm{El}$ término neoliberalismo es un neologismo -del griego neo (nuevo) y logo (palabra)- que hace referencia a una doctrina económica y política que considera contraproducente el intervencionismo estatal en materia social o en la economía y defiende el libre mercado capitalista como mejor garante del equilibrio y el crecimiento económicos http://es.wikipedia.org/wiki/Neoliberalismo. Tomado el 3 de febrero de 2008.

${ }^{5} \mathrm{El} \mathrm{22 \%}$ de la riqueza mundial pertenece a países en vías de desarrollo, que abarcan el 80\% de la población mundial. En estudios recientes, la situación se cree más crítica. Según Jim Davis, coautor de un estudio entregado a finales del 2006, la riqueza está concentrada en Norteamérica -especialmente Estados Unidosy Europa y en países como Australia y Japón. Estos en su conjunto poseen el $90 \%$ de la riqueza mundial y América Latina posee solo el 4\% de la riqueza personal del mundo, a pesar de su extensión y población. Davis Jim. www.BBCMundo.com. Noticia publicada el 5 de Diciembre de 2006. Tomado el 12 de Diciembre de 2006.
} 
comercial a nivel internacional es un proceso arduo, pero es al fin y al cabo un proceso irreversible.

\begin{abstract}
La prueba contundente de "no retroceso" del proceso de globalización es la constitución de los bloques económicos regionales como, por ejemplo, la Unión Europea y los Tigres Asiáticos, en Europa y Asia; y el NAFTA (Tratado de libre Comercio), GRAN (el Pacto Andino), el Mercado Común Centroamericano, CARICOM (La Comunidad del Caribe), y el MERCOSUR (Mercado Común del Sur) en el continente americano, entre otros
\end{abstract}

Frente a la innegable injerencia de la armonización contable en nuestro ordenamiento normativo, debe considerarse con un grado de alta importancia, los procesos que permiten mantener la identidad económica propia y al mismo tiempo, ingresar en los procesos irreversibles del mundo globalizado en el cual se esta inmerso. Caso contrario lleva a desconocer o erróneamente a interpretar que existe una igualdad o similitud entre los estándares económicos de países conocidos como desarrollados, con los que rigen la economía de los países Latinoamericanos.

Encaminarse en los propósitos de intercambio comercial a nivel mundial, implica entrar también en la dinámica de armonización de las normas no son sólo a nivel contable, sino también comercial y del ejercicio de la profesión. Hacerlo facilitaría los procesos contables llevados por las grandes empresas exportadoras y/o las multinacionales, pero para la economía Colombiana, de pequeñas y medianas empresas, no se ofrecen beneficios. Adoptar estas normas, dejará en desventaja a las PYMES Colombianas frente a las grandes potencias en tanto son difícilmente igualadas por sus economías a gran escala.

Por lo anterior se hace necesario aclarar que los estándares internacionales pueden ser acogidos como una exigencia de la globalización para lo cual debe haber preparación, desde el punto de vista académico, haciendo que la disciplina contable dentro del ámbito nacional e internacional, pueda tener un claro entendimiento en cuanto al lenguaje de sus sistemas, a la luz de los resultados de las negociaciones efectuadas como producto del intercambio comercial entre las naciones. Por lo anterior se puede hablar de una primera idea clara en cuanto a la armonización de lo contable como, el proceso de adaptación de las normas nacionales a las internacionales, que manteniendo ciertos contenidos apropiados da cuenta de los intereses propios del ámbito jurídico y

6 TALLA RAMOS Mg. SABINO. La Globalización y La Armonización Contable. http:/ / sisbib.unmsm.edu.pe/BibVirtual/Publicaciones/quipukamayoc/1999/primer/global.htm. tomado el 21 de febrero de 2008. 
económico del entorno particular. Con ello se busca preservar la independencia y discrecionalidad en los procesos informativos - contables adecuados a cualquier sistema político que adelante acciones autónomas a favor del desarrollo social.

\section{Por qué y para qué la armonización contable}

En materia contable hay aspectos en los cuales se habla un lenguaje cada vez con mayores similitudes, como el referirse a las normas de auditoria o a los principios de contabilidad generalmente aceptados. Sin embargo, cada país tiene su propia reglamentación y se encuentran aspectos no tan familiares entre economías diversas y situaciones particulares. En Colombia la contabilidad, fuente de información en la empresa, hace referencia a una economía meramente física y no a una economía intangible. Es decir, una economía física trabaja con relativa certidumbre para valorar y contar lo tangible, pero no para medir intangibles, cuyos bienes son de difícil cuantificación y valoración. Mientras no se valore intangibles, difícilmente se presentará la real situación financiera - patrimonial de las empresas. He aquí la referencia a economía de conocimiento. Este tipo de bienes, cuantificados en las grandes empresas y sobre todo en las multinacionales por su notable valor, no son significativos en nuestras empresas nacionales, generalmente por su tamaño o tal vez y quizá aún más, porque no hacen parte de nuestra cultura empresarial.

Se considera como aspecto relevante de la influencia de la armonización contable, desde el punto de vista académico, el análisis e interpretación del considerable número de normas existentes en Colombia, frente a la limitante de otros con los cuales se tienen relaciones de índole comercial. Un claro ejemplo se evidencia cuando se sesga de acuerdo a lo señalado en una de las leyes más importantes para el ejercicio de la contaduría pública en nuestro país: la ley 43 de 1990, en la cual en sus artículos 1, 10 y 35 , refieren a la exclusividad de los profesionales previamente inscritos en la Junta Central de Contadores, para poder dar fe pública a los estados financieros de los entes económicos obligados a tal fin. Circunstancia contraria se observa en el ámbito internacional, específicamente en nuestra zona de frontera Colombo Venezolana, en la cual se presenta el fenómeno del modelo venezolano. Dentro de su ordenamiento jurídico contable, abre la posibilidad para que otros profesionales diferentes a los contadores Públicos, los administradores de empresas, puedan dar fe pública a los informes financieros de los entes económicos en dicha nación, obligados de acuerdo a la ley de cooperativas. Por otra parte Colombia es el único país que cuenta con la figura del revisor fiscal. ¿Se tendría que abolir esta situación particular en nuestro país? o ¿los demás países estarían dispuestos a asumirlo?

Como se ha señalado, la armonización surge como necesidad de adaptarse a nuevas exigencias, entre regiones, países y empresas internacionales. Hoy más que nunca, las distancias son extraordinariamente cortas entre las naciones y el concepto de frontera pasó de ser algo meramente divisorio para convertirse en oportunidad de relaciones 
dinámicas. En este contexto de internacionalización de la economía, el papel de las fronteras es trascendental. Un ejemplo claro como se ha mencionado, lo constituye el intercambio cultural entre las naciones hermanas desde el punto de vista pedagógico, cuando Colombianos y Venezolanos concomitantemente, cruzan la frontera para afianzar sus conocimientos de acuerdo a la formación profesional que en primera instancia hayan recibido en sus estudios de pregrado, en el caso especifico de los Contadores Públicos.

Por lo anterior, si bien se retoman aspectos que permiten entender la vulnerabilidad que enfrentan las economías llamadas tercer mundistas, la presente reflexión se encamina a la toma de conciencia de la importancia de lo contable en las transformaciones que vive nuestra sociedad latinoamericana, la realidad colombiana y en el caso referente, la formación de alumnos y profesionales del área Contable de la zona colombovenezolana, particularmente del nor-oriente Colombiano, teniendo presente, la realidad económico financiera de Colombia y Venezuela en la cual se puede observar actualmente, cambios de trascendencia que se mencionan a continuación:

\section{1- Reconversión de la moneda al Bolivar Fuerte (1 de enero) y}

2- Aplicación de Normas Internacionales de Información Financiera (NIC-NIIF)

$y$ sus interpretaciones, emitidas por la Junta de Normas Internacionales de Contabilidad (LASB, por sus siglas en Inglés) y las Normas Internacionales de Auditoria (NLA), emitidas por la Federación Internacional de Contadores (IF AC, por sus siglas en Inglés) (31 de diciembre).

Estos dos cambios, tendrán efectos inmediatos en las relaciones de intercambio en la zona de frontera, no solo por las nuevas denominaciones monetarias, sino por la información financiera que se enviarán los inversionistas comunes de los dos países.

\section{INTERCAMBIO DE INFORMACIÓN FINANCIERA BINACIONAL}

No se puede afirmar que las normas de contabilidad de Venezuela y de Colombia sean iguales en la actualidad, aunque si tienen algunas aplicaciones similares. Por ejemplo. Hasta el 31 de diciembre del 2006, tanto en Venezuela como en Colombia, se aplicaron los ajustes por inflación. Venezuela los aplicó en el 2007 (se calcularon al final del año en dicho país), mientras que Colombia los eliminó. Esta sola diferencia presentará una asimetría en la información financiera del año 2007 entre los dos países.

De no aplicarse los estándares internacionales de contabilidad en Colombia a partir del 31 de diciembre de 2008, como balance de apertura con arreglo a las NIIF (First IFRS 
Financial Statements), los estados financieros locales deberán ser convertidos a dichas normas, para hacer comparable la información financiera, y en los casos de inversionistas binacionales, para consolidar los estados financieros de lo grupos económicos establecidos en los dos países.

En otras palabras, el problema en el futuro será de Colombia, no de Venezuela. Por cuanto a nadie se le ocurrirá que los informes financieros de compañías de otras naciones, sean convertidos primero a las reglas de contabilidad de nuestro país, para poder ser interpretados y analizados de manera homogénea con la información local. Claro que NO. Para poder comprender dicha información y hacerla comparable, deberemos convertir los informes elaborados bajo regulación contable local a las NIIF, con un costo muy alto por el doble procesamiento. ${ }^{7}$

De lo anteriormente, surge la imperante necesidad de formación de los estudiantes y profesionales del área contable, que atienden o se enfrentan a esta realidad en los negocios binacionales y también internacionales con otros países con los cuales Colombia tiene relaciones comerciales. Es necesario, una revolución de los propios esquemas mentales frente a la responsabilidad social que atañe a la profesión contable y que surge como respuesta a los cambios inevitables, interpelando la forma de ver el mundo y los acontecimientos que llegan para analizar, debatir, proponer y asumir nuevos retos. Es la revolución de los propios esquemas mentales de la cual está dispuesto a apropiarse quien busca una vida digna de todo ser humano, de la sociedad y que tiene en cuenta, que quienes actúan y planean qué hacer, subsisten. A lo largo de la historia se ha comprobado que sobreviven los de mayor capacidad de adaptación. No es cuestión de decisión personal si no de asumirlo como un hecho y prepararse para el y qué mejor que aunar esfuerzos en pro de la preparación de todos los estudiantes y profesionales Contables del país y de nuestras regiones particulares. Esta revolución de pensamiento, de esquemas, se desarrolla también y principalmente en la academia.

Desde un acercamiento a los Pensum de las universidades del nororiente colombiano y algunas de Venezuela, se proponen modificaciones en el proceso de formación de Contadores Públicos. Formación que lleve a adquirir capacidades prácticas y/o procedimentales en el ámbito de la profesión, pero también, de sentido investigativo y crítico, permitiendo desarrollar, potencializar y fortalecer en el estudiante y profesional, destrezas de análisis frente a los planteamientos mencionados.

Pero se hace referencia no solo a la formación de estudiantes, sino también a la de los profesionales en ejercicio, quienes necesitan en este momento particular, estar al tanto de los cambios y fundamentalmente, prepararse para nuevos métodos y maneras de ejercer y presentar la contabilidad, para analizar el conocimiento y la practica contable.

${ }^{7}$ VASQUEZ TRISTANCHO, Gabriel. Venezuela Adelanta A Colombia En Aplicación De Niif. Columnista Vanguardia Liberal Bucaramanga, 25 de Septiembre de 2007. 
Retos que implica ser un contador en continuo crecimiento profesional, en constante preparación y con apertura al conocimiento. Toda esta información y preparación la pueden ofrecer los centros universitarios de la región a sus egresados en Contaduría Pública y en general a los profesionales que deseen continuar con su proceso de formación -que deberían ser todos-, así como las diversas instituciones nacionales, creadas como apoyo al ejercicio de tan importante labor social. Todos los esfuerzos hechos para cualificar la formación profesional, redunda en beneficio de las nuevas generaciones, necesitadas de profesionales con estudios serios y profundos, no sólo en aspectos prácticos, sino también de tipo investigativo y pedagógico que contribuyan a una formación profesional cualificada en nuestro país, en los pregrados y más allá de ellos.

"La debilidad en la formación doctoral al interior de la comunidad contable es evidente. Al finalizar los noventa, habia cinco docentes con estudios en el exterior. De este grupo, solo cuatro tenian producción académica reconocida, estos docentes contribuyeron a la cualificación de los planes de estudio dentro de sus universidades's

\section{LO CONTABLE EN EL ÁMBITO NORMATIVO}

Habiendo hecho un acercamiento al concepto de armonización y comprendiendo la inmersión en el proceso de globalización llevado a cabo en el mundo y que es irreversible.

\section{Aspecto normativo general y normas contables de nuestro país}

Para hablar de aspecto normativo, se aborda el concepto de norma, entendiéndolo como una convención reglamentaria que se debe seguir o a la cual se deben ajustar las conductas, tareas y/o actividades, "regla sobre la manera como se debe hacer o está establecido, que se haga una determinada cosa". Algunas características de las normas son el que llevan a conseguir algo, una meta, por ser convenciones sociales se pueden modificar o abandonar, sea justificadamente o no, la norma beneficia a alguien, deben ser compatibles con ciertas leyes, sino no podrían imponerse. Lo normativo hace relación al conjunto de normas aplicables a una determinada materia o actividad. Un modelo normativo por su parte, es el marco bajo el cual se inician las normas aplicables en determinado campo y se construye teniendo en cuenta el entorno en el cual se va a desarrollar y aplicar dicha regulación.

Por ejemplo, la Ley Sarbanes-oxley de los Estados Unidos bajo el mandato de George Bush. Estableció una nueva junta de normatividad contable del Instituto

8 ASCOLFA. Epistemología, investigación y educación en las ciencias administrativas. 2007. PopayánColombia. Editorial Torre Blanca. Pág. 281.

${ }^{9}$ OCEANO UNO COLOR. Diccionario Enciclopédico. 2001. Editorial Océano. Término: norma. 
Norteamericano de Contadores Públicos (AICPA). Surge a raíz de serios escándalos financieros como los sucesos de Enron, que encontraron en el gobierno y organismos profesionales tal reacción. En el caso de la Enron, se dieron actos intencionales de manipulación de la información, que presentaron estados financieros contrarios a la realidad de la empresa. Bajo esta situación o contexto se tomaron medidas para modificar el modelo normativo que respondiera a sancionar este tipo de sucesos delictivos. De allí que los objetivos principales de la ley sean monitorear la industria de la contabilidad, sancionar a los ejecutivos que cometan fraudes corporativos e incrementar el presupuesto para auditores e investigadores de SEC (Securities and Exchange Commissión). Finalmente, la meta a conseguir, recuperar la confianza de los inversionistas en los EE.UU y el fundamento, sancionar este tipo de conducta para buscar reducirlas o eliminarlas.

Debido a que cada país tiene contextos particulares y diferentes, se hace necesario que establezcan elementos normativos propios. En Colombia, las normas contables son aplicadas, generalmente hablando de las pequeñas y medianas empresas, como necesidad ante las obligaciones que se asumen frente al Estado o como un requisito exigido por los diferentes entes económicos. En muy pocas oportunidades posibilitan el desarrollo de las mismas empresas y regiones, a través de la maximización de recursos que cada una posee o también orientadas a crear alianzas estratégicas definidas a nivel interno o por mecanismos aplicados exteriormente, como el caso de los clusters ${ }^{10}$. Tales oportunidades las colocaría en ventaja frente a otras. Esta situación de las PYMES, al referirse a la armonización contable, es motivo de otro análisis como una reflexión que marca la desproporción de la contabilidad de las grandes compañías multinacionales de los países llamados desarrollados, frente a las que utilizan las pequeñas y medianas compañías nacionales.

Con lo anterior, al hablar de normas contables en Colombia, se hace referencia al conjunto de normas que se aplican en el ejercicio de la contabilidad o actividades relacionadas con la ciencia contable en general, según el artículo 2 de la ley 43 de 199011: En el inciso, a saber "todas aquellas actividades conexas con la naturaleza del Contador Público", se tiene en cuenta que en Colombia, el marco normativo está fundado en lo teórico, tanto en el ejercicio de la contabilidad como en el ejercicio de la profesión contable. Las Normas Contables hacen referencia por un lado, a los principios de

\footnotetext{
10 Situación en los mercados de economías relacionadas, que permite asociar o agrupar en determinado espacio físico a empresas o establecimientos comerciales cuyo objeto social es convergente, con el fin de ser más atrayentes y fuertes en el mercado. Esta situación tiene una presencia relevante en la zona de frontera mencionada en el presente trabajo y se considera una ventaja comercial a explorar de manera consciente y dinámica en el ámbito contable.

${ }^{11}$ Todas aquellas actividades que implican organización, revisión y control de contabilidades; Certificaciones y dictámenes sobre estados financieros; Certificaciones expedidas con fundamentos en los libros de contabilidad; Revisoría fiscal; Servicios de auditoria; Todas aquellas actividades conexas con la naturaleza del Contador Público
} 
contabilidad generalmente aceptados, bajo los cuales se deben llevar y presentar todos los informes que cumplan con un objetivo financiero o administrativo, pero también a las normas que se observan, estipuladas en la ley 43 de 1990 para los Contadores Públicos Colombianos, quienes responden por ella ante el tribunal disciplinario de nuestra profesión, a saber, La Junta Central de Contadores.

A nivel internacional la reglamentación contable está presidida por tres grupos de normas: Las normas internacionales de contabilidad (NIC), emitidas hasta el 2001, fecha a partir de la cual se reconocen como "Normas Internacionales de Información Financiera" (NIIF), resultado de estudios de diferentes entidades del área contable a nivel mundial, para estandarizar la información presentada en los estados financieros, la cual dificultaba la administración de las multinacionales, por las no pocas las diferencias en los informes presentados en sus países -por ejemplo EE.UU- frente al presentado en otros países de economías llamadas en vía de desarrollo. En primer periodo, estas normas fueron emitidas por el International Accounting Standards Committee, después, a partir de su sustitución por la International Accounting Standards Board. El segundo y tercer grupo lo constituyen los principios de contabilidad generalmente aceptados, GAAP y USGAAP esta última de aplicación en los Estados Unidos. "Debe recordarse que las USGAAP no tienen aplicación solo en EEUU, de alguna manera son normas internacionales, dado que en algunos paises y mercados se han adoptado, como es el caso de Canadá, Japón, Nueva Zelanda, en sus bolsas de valores, Puerto Rico y Panamá las implementaron a nivel nacional, aunque en el último caso es opcional su uso o el de la IFRS"12

Una vez más se evidencia la importancia y necesidad de estudios profundos por parte de los estudiantes de Contaduría Pública que lleven a una apropiación de los retos que se presentan a la profesión contable. Por ello se trae a mención un convenio con el cual se cuenta para beneficio de esta importante tarea, el convenio Andrés Bello, cuyos orígenes se remontan a enero de 1970 y del que forman parte países como Bolivia, Colombia, Chile, Ecuador, España, Panamá, Perú y Venezuela; con la finalidad primordial de realizar esfuerzos conjuntos en favor de la educación, la ciencia, la tecnología y la cultura. De modo, que entre otras medidas, estos Estados miembros del Convenio: - Fomentarán el otorgamiento de becas recíprocas. - Reconocerán los estudios primarios o de enseñanza general básica y de educación media o secundaria, mediante tablas de equivalencia que permitan la continuidad de los mismos o la obtención de los certificados correspondientes a cursos, niveles, modalidades o grados aprobados en cualquiera de ellos. - Reconocerán los diplomas, grados o títulos que acrediten estudios académicos y profesionales expedidos por instituciones de educación superior de cada uno de ellos, a los solos efectos del ingreso a estudios de especialización, máster y doctorado.

12 FRANCO RUIZ, Rafael. 2005. Réquiem por la confianza. Armenia, Colombia. Editorial Investigar Editores. Pág. 117 


\section{LAS ZONAS DE FRONTERA Y SU INFLUENCIA EN LO CONTABLE}

Del mismo modo como las distancias se han acortado, el concepto de frontera pasó a ser un vínculo de dinamismo en todos los ámbitos. Por su importancia se plantea, la injerencia de la armonización de lo contable en las regiones fronterizas de Colombia. En nuestro país, el concepto de frontera abarca dos connotaciones principales. Por un lado, la delimitación geográfica, política y militar y por otro, el control de tráfico de mercancías y movilidad de individuos. En este sentido, la constitución política permite el establecimiento de zonas de frontera como divisiones territoriales especiales, para las cuales hay un tratado determinado ${ }^{13}$. La ley 191 de 1995, ley de fronteras, delimita el concepto dando a entender que las zonas de integración fronteriza constituyen espacios para facilitar la interacción, en términos productivos de intercambio, a demás de permitir promover acciones en beneficio de orden bilateral. En este contexto, "la política de frontera en Colombia se reduce a zonas económicas especiales de exportación (Buenaventura, Ipiales, Valledupar y Cúcuta), asuntos fronterizos de la Comunidad Andina -CAN- y acuerdos de coordinación energética, cielos abiertos, transporte internacional de mercancias, migración y asuntos de seguridad'l4.

Si esto ocurre a nivel gubernamental, un aspecto a retomar y desarrollar constituye los procesos de integración frente a las regiones que no son fronterizas. Este potencial lo tienen las fronteras para promover y difundir los beneficios asociados a la integración comercial, tener en cuenta además, asuntos como: propiedad intelectual, desarrollo tecnológico, compras públicas, control de inversiones extranjeras, manejo ambiental, y sobre todo en nuestro caso, el intercambio cultural, educativo, académico y científico ${ }^{15}$. Facilitar el comercio es vital para las fronteras, esto comprende la armonización y simplificación de los procesos asociados al comercio internacional. En efecto, cada uno de estos factores tiene una implicación directa sobre el desarrollo de las fronteras, a propósito del avance del país, hacia una integración comercial, en la medida en que estas regiones sea una zona de intercambio de bienes. Pero la región fronteriza ha tenido un desarrollo inferior al resto del país, situación reflejada en los departamentos que la conforman, pues estos sólo aportan el 8\% del PIB ${ }^{16}$ y "el analfabetismo se promedia entre el 11\% y $20 \%$ de su población y su baja dinámica económica explica su baja tributación"'17.

\footnotetext{
13 Constitución política de Colombia, Art 287y 337.

14 Pronunciamiento del Dr. Antonio Hernández Gamarra, Contralor General de la República. Las Zonas de Frontera en los procesos de integración comercial. Cúcuta, 22 de Abril de 2005.

$15 \mathrm{Al}$ respecto y para el interés de la presente, a saber el aspecto educativo y científico, se puede consultar en la resolución No 05 del 90, Texto del tratado de la organización del convenio Andrés Bello, suscrito el 31 de Enero de 1970, sustituido por un nuevo convenio, suscrito en 1990, vigente a la fecha.

${ }^{16}$ El Producto Interno Bruto (PIB) es el valor total de la producción corriente de bienes y servicios finales dentro del territorio nacional, durante un periodo de tiempo. Ya que una economía produce un gran número de bienes, el PIB es la suma de tales elementos en una sola estadística. La cifra del PIB engloba la
} 
Sin embargo, las repercusiones de una armonización contable, en esta región del país traen también ciertas dificultades. No es novedad que Venezuela no esta dispuesto a entrar en este proceso o en cualquiera que sienta una imposición del "imperio". Ello presenta dificultades teniendo en cuenta que el comercio en esta región es fundamentalmente dependiente de la relación con Venezuela y va más allá incluso de las normatividades nacionales.

Diferentes posiciones frente a la situación plantean por un lado, el que los contadores públicos al verse vinculados a las propuestas que traigan las grandes multinacionales, tendrán un cierto grado de desventaja, dado que la contratación de estos profesionales será única y exclusivamente parte de las empresas extranjeras, y la contaduría pública como profesión liberal quedara relevada en todos los campos, dejando como producto el desplazamiento laboral a nivel nacional, y en las zonas de frontera, a largo plazo, al establecerse las empresas extranjeras, tendrá un mayor impacto sobre los contadores pues habrá escasez de demanda laboral. Otra repercusión frente a la competencia exterior es la inestabilidad tributaria a la cual nos vemos expuestos los colombianos.

Cada día nos encontramos frente a impuestos aplicables a los habitantes del común y a la producción nacional y para las inversiones extranjeras, se ofrecen excéntricos privilegios. A medida que se da una mayor apertura al comercio binacional, nos vemos invadidos de productos y empresas venezolanas que plantan sus establecimientos de comercio en la capital norte-santandereana. Al igual, está la oportunidad de tener una demanda mayor de los bienes que se ofrecen en nuestro país. Habrá mayor competencia en el mercado y se dará una oferta importante en mano de obra.

El mayor y más grande impacto del proceso de armonización de las normas contables, las tendrán que sobrellevar las micro, pequeñas y medianas empresas ya establecidas en las zonas fronterizas que junto con las del resto del país están representadas por el 98\% de la economía colombiana y de paso afectaría al fisco nacional ya que no contaran con la información contable para tasar los impuestos. Como se mencionó al inicio, de allí parte la preocupación de la adopción de estándares internacionales de contabilidad, auditoria, y contaduría, dado que esta es la política que esta implementando el estado colombiano para hacer más fáciles las negociaciones de los tratados de libre comercio, pues son una forma de adecuar nuestra legislación a los requerimientos de las multinacionales inversionistas en nuestro país.

producción corriente de bienes finales, valorada a precios de mercado y mide el ingreso de los factores de producción sin importar quien recibe el ingreso.

17 http://www.presidencia.gov.co/prensa_new/sne/2007/mayo/07/11072007.htm Tomado en 3 de febrero de 2008 


\section{PROPUESTA ACADÉMICA EN PRO DE RENOVAR LOS PENSUM DE CONTADURIA PÚBLICA DE LA REGION NORORIENTAL DE COLOMBIA}

Al abordar los planes de estudio de Contaduría Pública, se asume la responsabilidad de plantear un direccionamiento frente a los procesos educativos y áreas de formación. Una posible adaptación al proceso de la armonización contable se realiza al incluir una serie de materias que son necesarias en la formación. Dicho proceso debe estar encaminado por los directores de programa de las diferentes facultades de Contaduría Pública para brindar a los profesionales Colombianos los elementos necesarios para ser competitivos con los demás profesionales del exterior y estar a la par en conocimientos, adecuados al contexto en el que cada uno se desenvuelve, haciéndose necesario la construcción de un perfil profesional y ocupacional del contador publico en Colombia, con un programa académico que responda a la realidad en la cual se desarrolla, guardando el horizonte de la responsabilidad social y formación integral del profesional Contable.

Es el momento de hablar entonces, del aspecto pedagógico que envuelve la formación de la Contaduría Pública en Colombia.

“...Eventualmente se presentan propuestas que básicamente abordan el como enseñar, como diseñar el plan de estudios, en fin, pero en ellas ha estado ausente el principal componente de la educación: el pedagógico. Y la razón de esta ausencia es elemental, la mayoría de contadores públicos docentes no son pedagogos." 18

Esta es una de las falencias no solo en la realidad de las cátedras universitarias, sino también en los planes académicos de las facultades de contaduría pública, como formación de formadores en Ciencias Contables. Lo pedagógico deriva de preguntas tales como: ¿Qué se hace? ¿Qué es lo esencial? ¿Qué se puede aprender de manera independiente? ¿Qué es lo complementario y lo electivo? Entre otros tantos cuestionamientos que se deben formular. Otro aspecto indispensable es el investigativo. ¿Nuestras universidades dan espacios a la investigación contable?. Sin embargo, no basta con espacios para compartir conocimientos, son necesarias directrices que contribuyan a la formación investigativa de futuros profesionales, no solo en una, tal vez de manera aislada al proceso, sino constante en toda la carrera y la vida profesional.

18 SÁNCHEZ, Walter y GRAJALES Gherson. Contabilidad Conceptual e Instrumental. Ed. Investigar Editores. Pereira-Colombia.. 2006. Pág. 22. 
En igual importancia que el anterior están los sistemas de información contable. Frente a ello los pensums reflejan un estancamiento es sus actualizaciones y atraso tecnológico. El software contable juega un papel importante en el desarrollo y preparación de profesionales para ser competentes a los requerimientos de hoy, por ende, se propone que la tecnología sea empleada como soporte y apoyo a la tarea del Contador y que este camino se abra desde la formación académica, tanto para estudiantes de pregrado como para especialistas, sin dejar de lado el:

"Establecer vías de comunicación a través de las ventajas de los nuevos sistemas de información, intercambios estudiantiles y docentes, redes de apoyo internacional de los organismos y agremiaciones de la profesión." "'9

En pleno siglo XXI, cuando el fenómeno de la armonización trasciende a esferas políticas, económicas, culturales, sociales y también, inminentemente en el orden académico, se visualiza un nivel educativo que es el resultado del poco interés por parte del Estado y la misma sociedad, en idear modelos o estrategias que permitan la estructuración en las diferentes áreas y la conceptualización de las temáticas específicas a trabajar, acordes con las exigencias del momento. Analizar las posibles ventajas y desventajas de los modelos educativos vigentes, permite por tanto, emprender la marcha. Se hace necesario, iniciado el proceso formativo, se oriente un aspecto tan importante como es el aprendizaje y dominio de una segunda lengua, el "ingles", acompañado de la formación tecnológica (software contables), en tanto la profesión contable está íntimamente ligada con la comunicación de información económica y financiera, a través de sistemas electrónicos que a su vez exige, estar a la par de tantos requerimientos demandados en la actualidad. $\mathrm{Y}$ no es menos importante, propiciar espacios de investigación en cualquier ámbito relacionado con lo contable y direccionar todos los esfuerzos en pro de su fortalecimiento, y en general áreas como: Construcción del pensamiento contable, contabilidad inflacionaria, derecho internacional, mercantil y aduanero, paquetes contables y laboratorios.

De otra parte, la formación profesional integral se fundamenta en el desarrollo humano, haciéndose necesario combatir la postración mental del contador, brindando aspectos que fundamentales al momento de construir conocimiento: métodos de estudio, de lectura y de redacción, luchando así, por la implantación de un nuevo pensar donde lo humanístico reivindique su papel trascendental en este proceso de crecimiento y construcción de conocimiento, activo en todo momento. Por lo anterior, los centros de formación académica debe estimular desde un principio, unas bases sólidas a nivel ético y socio-antropológico, permitiendo que el profesional sea efectivamente.

19 FENECOP. Pensamiento contable-memorias de los congresos de estudiantes, Colombia 1984-2000. Cali, Colombia 2001. Editor William Rojas Rojas. 
La propuesta se enfoca en implementar al interior de la Universidad de Pamplona, el desarrollo de una serie de foros y seminarios tendientes a generar espacios de encuentro entre docentes y educandos, sobre temas en particular, con el noble propósito de concienciar a la población en referencia acerca de las implicaciones, alcances y limitantes del tema propuesto. Lo anterior se ha de proyectar hacia el interior de las Universidades de la región y de la zona de frontera, invitándolos a acercarse a esta realidad, para generar espacios de encuentro entre las mismas, siendo el encuentro binacional de Universidades el punto de congruencia, comenzando desde la Universidad de Pamplona, en cada una de sus sedes Pamplona, Villa del Rosario y Cúcuta, pasando por la Universidad francisco de Paula Santander, Universidad Libre, Universidad de Santander, así mismo la participación de la universidad de Mérida y la universidad Católica en Venezuela.

Los temas a tratar deberán ir desde la armonización contable, su injerencia al implementarse las Normas Internacionales de Contabilidad, sus ventajas y desventajas, las diferencias entre ambas naciones y su influencia al interior de cada uno de los programas de contaduría pública de las Universidades, donde seria inevitable una reforma en los contenidos programáticos, los cuales deben ir a la vanguardia de las nuevas tendencias de la contabilidad del mundo globalizado. En el tema de la academia, es innegable que ellas contribuyen desde la formación a construir profesionales idóneos, con un perfil laboral a explorar en cada una de las regiones en que se encuentren. En las zonas de frontera, hay particularidades a descubrir y explotar. Se ve allí, una clara oportunidad de ultimar nuestro análisis, en donde lo contable es un elemento vital en la constante transformación social que se vive en estas zonas geopolíticamente estratégicas para el desarrollo económico de nuestro país.

\section{REFERENCIAS}

- ASCOLFA. Epistemología, investigación y educación en las ciencias administrativas. 2007. Popayán- Colombia. Editorial Torre Blanca. Pág. 281.

- Constitución política de Colombia, Art. 287y 337.

- FENECOP. Pensamiento contable-memorias de los congresos de estudiantes, Colombia 1984-2000. Cali, Colombia 2001. Editor William Rojas Rojas.

- FRANCO RUIZ, Rafael. Réquiem por la confianza. Editorial Investigar Editores 2005. Armenia, Colombia. Pág. 117.

- FRANCO RUIZ, Rafael.

- http://www.gratisweb.com/contabilidadinter/CONTABILIAD_INTERNACIO NAL. 9 de Enero de 2007. 
- gamarRA HERNÁNDEZ, Antonio. Contralor General de la República. Pronunciamiento: Las Zonas de Frontera en los procesos de integración comercial. Cúcuta, 22 de Abril de 2005.

- http: //www.BBCMundo.com: Noticia publicada el 5 de Diciembre de 2006.

- http://es.wikipedia.org. Termino: Globalización. Se tomó la información el dia 9 de enero de 2007.

- http://es.wikipedia.org/wiki/Asociaci\%C3\%B3n_Latinoamericana_de_Libre_Co mercio. Tomado el 3 de febrero de 2008.

- http://www.presidencia.gov.co/prensa_new/sne/2007/mayo/07/11072007.htm Tomado en 3 de febrero de 2008.

- OCEANO UNO COLOR. Diccionario Enciclopédico. 2001. Editorial Océano.

- PUC. Plan único de cuentas para comerciantes. 2001. Editorial Nueva Legislación LTDA.

- SÁNCHEZ, Walter y GRAJALES Gherson. Contabilidad Conceptual e Instrumental. Ed. Investigar Editores. Pereira-Colombia. 2006. Pág. 22.

- TAlla RAMOS, Mg. SABINO. La Globalización y La Armonización Contable. http://atenea.unicauca.edu.co/ gcuellar/globalizacion.htm. Consultado el 3 de febrero de 2008.

- VASQUEZ TRISTANCHO, Gabriel. Venezuela Adelanta A Colombia En Aplicación De NIIF. Columnista Vanguardia Liberal Bucaramanga, 25 de Septiembre de 2007.

- Referencias para los pensum. Las páginas Web de cada Universidad. 